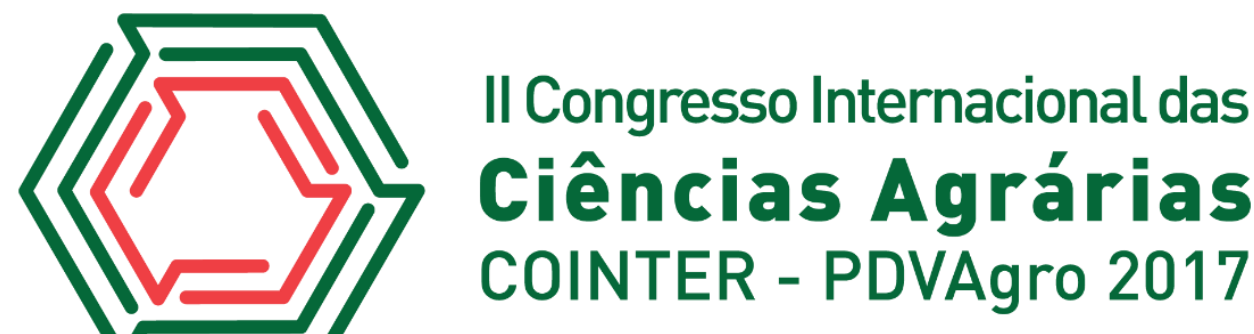

\section{GERMINAÇÃO E CRESCIMENTO DE Salvia hispanica L. SOB DIFERENTES SUBSTRATOS E VOLUMES DE ÁGUA}

\author{
Apresentação: Pôster
}

Kleane Targino Oliveira Pereira ${ }^{1}$; Emanoela Pereira de Paiva ${ }^{2}$; Francisco Vanies da Silva $\mathrm{Sá}^{3}$; Brenna Rafaela Verissimo dos Santos ${ }^{1}$; Salvador Barros Torres ${ }^{4}$

\section{Introdução}

Salvia hispanica L. pertence à família das Lamiaceae, distribuídas por varias regiões do mundo, originaria da região que se estende do centro-oeste do México até o norte da Guatemala, além das regiões como o Sul da África, América Central, América do Norte, América do Sul e Ásia Sul-Oriental (AYERZA; COATES, 2004), é utilizada no combate a redução de doenças cardiovasculares, colesterol, triglicerídeos, obesidade e regulação do intestino, bem como prevenção de doenças como a diabetes do tipo II e de alguns tipos de câncer (JIN et al., 2012).

Sua propagação é realizada via seminífera, e o processo germinativo na semente pode ser afetado por fatores internos, externos ou ambientais (LUZ et al., 2014), uma vez que as sementes requerem um nível adequado de hidratação, levando a retomada do metabolismo e conseqüente crescimento do eixo embrionário, sendo que quanto maior a quantidade de água disponível para as sementes, mais rápida será a absorção (CARVALHO; NAKAGWA, 2000). Já o substrato deve fornecer as sementes condições ideais de aeração, estrutura, capacidade de retenção de água, sanidade e proporção adequada entre a disponibilidade de água e aeração para evitar que a película de água envolva completamente a semente e diminua a entrada e absorção de oxigênio (ANDRADE et al., 2006).

\footnotetext{
${ }^{1}$ Mestrandas em Fitotecnia pelo Programa de Pós-Graduação em Fitotecnia (PPGF), Universidade Federal Rural do Semi-Árido (UFERSA), kleane_rn@hotmail.com; bre.rafa@ hotmail.com

${ }^{2}$ Doutora em Fitotecnia, Universidade Federal Rural do Semi-Árido (UFERSA), emanuelappaiva@ hotmail.com

3 Doutorando em Engenharia Agrícola, Universidade Federal de Campina Grande (UFCG), vanies_agronomia@hotmail.com

4 Professor e Pesquisador da EMPARN/UFERSA, Universidade Federal Rural do Semi-Árido (UFERSA), sbtorres@ufersa.edu.br
} 
Portanto, o presente trabalho tem por objetivo avaliar de diferentes volumes de água em diferentes substratos na germinação de sementes de $S$. hispanica, uma vez que não há recomendações para esta espécie.

\section{Fundamentação Teórica}

O excesso de umidade provoca decréscimo na germinação, pois impede a penetração de oxigênio e reduz todo o processo metabólico resultante, além de aumentar a incidência de fungos, levando à redução no vigor (MELO et al., 2005), uma vez que o grau de umidade do substrato pode inferir no processo de germinação. $\mathrm{O}$ substrato quando adequado à espécie proporciona um ambiente ideal para o crescimento das raízes, resultando no desenvolvimento de uma planta de qualidade (KÄMPF et al., 2006). Contudo, não se tem um substrato ideal para a germinação, o que prejudica a avaliação da qualidade das sementes (OLIVEIRA; FARIAS, 2009).

Diante do exposto trabalhos vêm sendo desenvolvido com intuito de obter volume de água e substrato para cada espécie, como em sementes de espécies agrícolas (AMARO et al., 2014; ARAÚJO et al., 2014).

\section{Metodologia}

As sementes de S. hispanica foram adquiridas junto aos produtores de Santana do Livramento, Rio Grande do Sul, safra 2013/2014.

Os substratos utilizados foram papel toalha (tipo Germitest ${ }^{\circledR}$ ) e mata-borrão, umedecidos inicialmente em seis volumes de água equivalentes a 1,5; 2,0; 2,5; 3,0; 3,5 e 4,0 vezes a massa do papel seco. Para o substrato de papel toalha, este foi organizado na forma de rolo sendo utilizadas três folhas por rolo, para o substrato mata-borrão utilizaram-se duas folhas, onde as sementes foram semeadas sobre e em seguida foram acondicionadas em caixas plásticas transparentes $(11$ x 11 x 3,5 cm), tipo "gerbox". Posteriormente foram acondicionados em seguida, foram colocados em câmara de germinação do tipo Biochemical Oxygen Demand (B.O.D.) com fotoperíodo de oito horas.

O teste de germinação foi acompanhado por oito dias, considerando-se como plântulas normais a emissão da raiz primária e parte aérea da plântula (BRASIL, 2009). Para a determinação do tempo médio de germinação, os dados foram submetidos para os cálculos do tempo médio de germinação, a equação proposta por Schuab et al. (2006). 
No final do teste de germinação, as plântulas normais de $S$. hispanica foram avaliadas: o comprimento de plântula da parte aérea e da raiz primária. O delineamento experimental adotado foi o inteiramente casualizado, em esquema fatorial 2 x 6, com quatro repetições de 50 sementes.

Os dados foram submetidos à análise de variância pelo teste ' $\mathrm{F}$ ', com auxílio do programa computacional Sistema para Análise de Variância - SISVAR ${ }^{\circledR}$ (FERREIRA, 2011).

\section{Resultados e Discussão}

Para as variáveis percentagem de germinação e tempo médio de geminação, verificou-se influência significativa $(p<0,05)$ dos substratos, em que as sementes germinadas no substrato mataborrão obtiveram maior percentagem de germinação e o menor tempo médio de germinação, em comparação com o substrato papel toalha do tipo Germitest ${ }^{\circledR}$, denotando que o substrato mataborrão é mais eficiente para a germinação de sementes de $S$. hispanica (Gráfico 1A e B). Resultados semelhantes foram observados por Azeredo et al. (2010), em que o substrato mata-borrão favoreceu a germinação das sementes de repolho (Brassica oleracea var. Capitata L.) em comparação com o papel toalha.
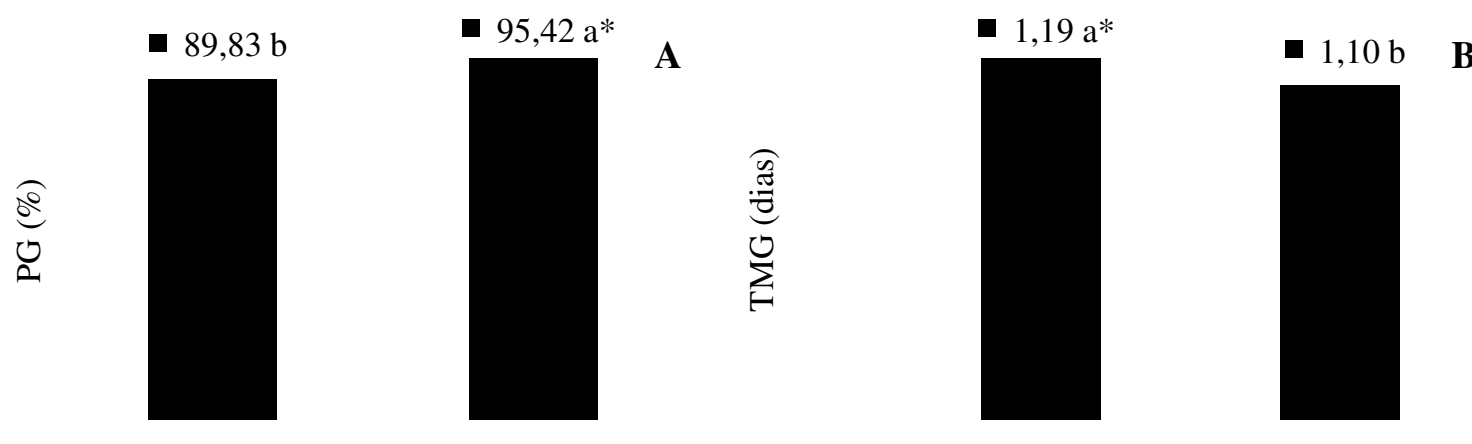

\footnotetext{
*Letras iguais não diferem perante o teste de Tukey ao nível de $5 \%$ de probabilidade $(\mathrm{p}<0,05)$.
}

Gráfico 1 - Percentagem de germinação, PG (A) e tempo médio de germinação, TMG (B) de sementes de $S$. hispanica germinadas nos substratos de papel Germitest ${ }^{\circledR}(G)$ e mata-borrão (MB) em diferentes volumes de água. Fonte: Própria

Influência significativa da interação substratos e volumes de água foram verificada para as variáveis comprimento da parte aérea e da radícula das plântulas (Gráfico 2A e B).

Para o comprimento da parte aérea e radicular das plântulas germinadas em papel toalha, verificou-se que o comprimento da parte aérea aumentou em $0,65 \mathrm{~cm}$ para cada aumento unitário no volume de água, ao passo que a radícula respondeu de forma inversa, reduzindo o crescimento em 
$1,08 \mathrm{~cm}$ por aumento unitário do volume de água (Gráficos 2A e B). Para o papel mata-borrão, verificou-se comportamento quadrático para o comprimento da parte aérea, com o maior comprimento $(2,81 \mathrm{~cm})$ sob o volume estimado de 2,6 vezes o peso do papel, com redução progressiva do crescimento em níveis de umedecimento maiores; todavia, não foi verificado efeito significativo para o comprimento radicular, com valor médio de $5,12 \mathrm{~cm}$.

A redução do crescimento da radícula e o aumento do comprimento da parte aérea também foram observados por Amaro et al. (2014), em sementes de repolho e Araújo et al. (2014) em sementes de cabacinha (Luffa operculata).
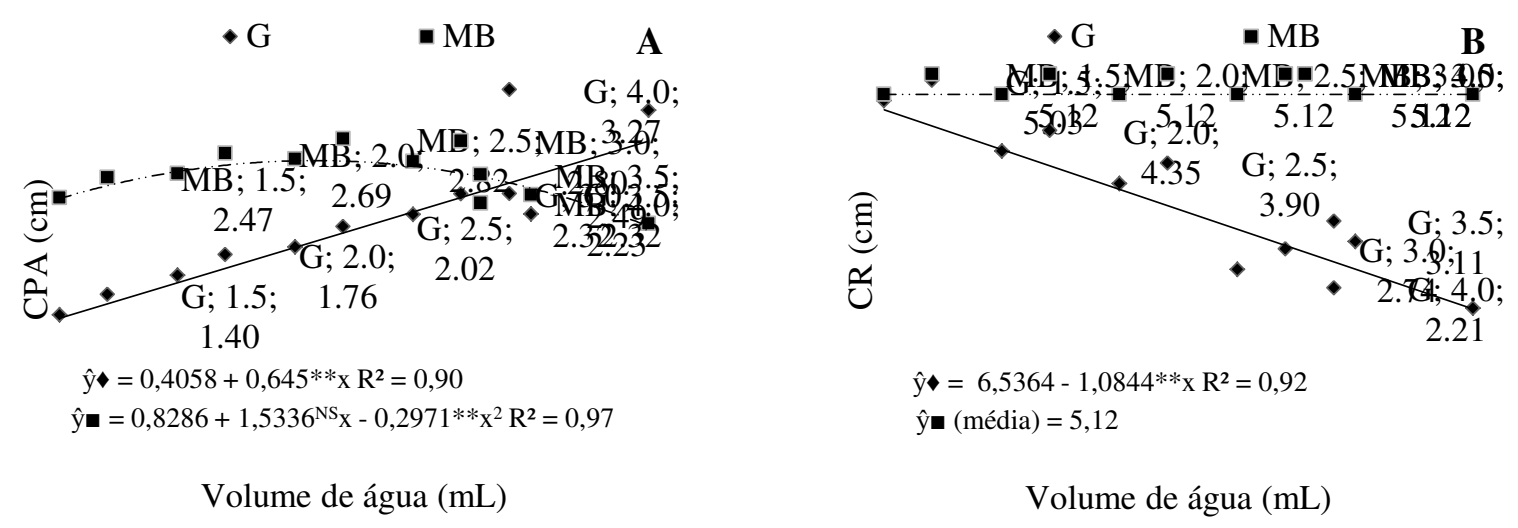

\footnotetext{
${ }^{\mathrm{NS}}, * * \mathrm{e} *=$ não significativo, significativo a 0,01 e $0,05(\mathrm{p}<0,01$ e $\mathrm{p}<0,05)$ de probabilidade, respectivamente.

Gráfico 2 - Comprimento da parte aérea, CPA (A), radícula, CR (B) de plântulas de S. hispanica L. germinadas nos substratos de papel Germitest ${ }^{\circledR}(\mathrm{G})$ e mata-borrão $(\mathrm{MB})$ em diferentes volumes de água.
}

\section{Conclusões}

O teste de germinação de sementes de S. hispanica deve ser conduzido no substrato mataborrão (sobre papel) com quantidade de água entre 2,5 a 4,0 vezes o peso do substrato seco.

\section{Referências}

AMARO, H. T. R. et al. Umedecimento do substrato e temperatura na germinação e vigor de sementes de melão. Semina: Ciências Agrárias, Londrina, v. 35, n. 3, p. 1119-1130, 2014.

ARAÚJO, P. C. et al. Different water volumes in the substrate and temperatures for germination of cabacinha seeds. Horticultura Brasileira, Brasília, v. 32, n. 3, p. 367-370, 2014.

AYERZA, R; COATES, W. Composition of chia (Salvia hispanica) grown in six tropical and subtropical ecosystems of South America. Tropical Science, Nova Jérsei, v. 44, n. 3, p. 131- 135, 2004. 
AZEREDO, G. A. et al. Umedecimento e substratos para germinação de sementes de repolho. Pesquisa Agropecuária Tropical, Goiânia, v. 40, n. 1, p. 77-82, 2010.

BRASIL. Ministério da Agricultura, Pecuária e Abastecimento. Regras para Análise de Sementes. Ministério da Agricultura, Pecuária e Abastecimento. Secretaria de Defesa Agropecuária. Brasília, DF: MAPA/ACS, 2009. 395 p.

CARVALHO, N.M. \& NAKAGAWA, J. Sementes: ciência, tecnologia e produção. 4.ed. Jaboticabal: Funep, 2000. 588p.

FERREIRA, D. F. Sisvar: A computer statistical analysis system. Ciência e Agrotecnologia, Lavras, v. 35, n. 6, p. 1039-1042, 2011.

JIN, F.; et al., Supplementation of milled chia seeds increases plasma ALA and EPA in postmenopausal women. Plant Foods for Human Nutrition. v. 67, p.105-110, 2012.

KÄMPF, A. N.; TAKANE, R.; SIQUEIRA, P. T. V. Floricultura - técnicas de preparo de substratos. Brasília: Tecnologia Fácil. 2006. 132p

LUZ, F.N.; et al.,. Interferência de luz, temperatura, profundidade de semeadura e palhada na germinação e emergência de Murdannia nudiflora. Comunicata Scientiae, v. 5, n. 1, p. 26-33, 2014.

MELO, R. R.; FERREIRA, A. G.; JÚNIOR, F. R. 2005. Efeitos de diferentes substratos na germinação de sementes de angico (Anadenenthera columbrina(Vell) Brenan) EM. Revista científica eletrônica de engenharia florestal., edição número 5 , n 8 p 1-8 5 jan.

OLIVEIRA, A. K. M.; FARIAS, G. C. Efeito de diferentes substratos na germinação de sementes de Terminalia argentea (Combretaceae). Revista Brasileira de Biociências, v. 7, n. 3, p. 320-323, 2009.

OROZCO, B.; ROMERO, M. R. La chía, alimento milenario. Industria alimentaria (México, D.F.), Cidade do México, v. 25, n. 5, p. 20-29, 2003.

SCHUAB, S. R. P. et al. Potencial fisiológico de sementes de soja e sua relação com a emergência das plântulas em campo. Acta Scientiarum. Agronomy, Maringá, v. 28, n. 4, p. 553-561, 2006. 